\title{
Contralateral gaze deviation after frontal lobe haemorrhage
}

\author{
JAMES A SHARPE, ROBERTA L BONDAR, WILLIAM A FLETCHER
}

From the Neuro-ophthalmology Unit, Division of Neurology, the Playfair Neuroscience Unit, Toronto Western Hospital, and the Departments of Medicine and Ophthalmology, University of Toronto, Canada

SUMMARY Contralateral deviation of the eyes was sustained for a week in a patient with discrete subcortical frontal lobe haematoma. When deviation recovered, ipsilateral saccades were hypometric and saccadic latencies were prolonged in both horizontal directions. Smooth pursuit was paretic during tracking toward the side of the haematoma. Pursuit gain was higher during tracking to the contralateral side. Smooth eye movement imbalance may explain the unusual finding of contralateral gaze deviation with frontal lobe damage.

Acute unilateral cerebral hemispheric lesions often cause ipsilateral conjugate deviation of the head and eyes and loss of contralateral saccades. ${ }^{1-3}$ Within variable intervals of several hours to days, full saccades are evident. Although the transient cerebral gaze palsy is often attributed to frontal lobe lesions ${ }^{4}$ pathological confirmation of lesions confined to the frontal lobe is not available. Extensive deep hemispheric involvement of the frontal and parietooccipital corticofugal projections is the rule. ${ }^{1}$ Brief deviation of the eyes away from the side of a cerebral lesion can be a manifestation of epileptic discharge. Sustained contralateral ocular deviation is a feature of haemorrhage into the caudal thalamus. ${ }^{5,6}$ This deviation to the "wrong" side has also been recognised in a patient with an extensive parietal and frontal lobe haemorrhage above the thalamus. ${ }^{7}$ We report prolonged contralateral deviation in a patient with a discrete haematoma of the frontal lobe.

\section{Case report}

A 16-year-old girl was concussed after being thrown off her motorcycle 2 hours before admission to hospital. She was stuporous but moved all limbs spontaneously. The respiratory pattern, pupillary size and reactivity, and skeletal motor responses were normal. The eyes were deviated conjugately

Address for reprint requests: Dr James A Sharpe, Division of Neurology, Toronto Western Hospital, 399 Bathurst Street, Toronto M5T 2S8, Canada.

Received 13 March 1984 and in revised form 14 June 1984.

Accepted 16 June 1984 to the extreme left. They were easily moved to the mid- $\stackrel{+}{\infty}$ position by oculocephalic manoeuvres, but vigorous heado -turning to the left was required to move the eyes fully to the right. Caloric vestibular stimulation was not performed since oculocephalic manoeuvres produced full deviation Apart from fractures of the right zygoma and maxilla, the remainder of the physical examination was normal.

A CT scan on the day of admission showed a discrete righr frontal lobe haematoma (figure 1). Two days after admission the patient could sit erect but was unresponsive to verbat commands. The visual fields were intact to threat. She hel $\$$ her head in the mid-position but the leftward ocular deviation was unchanged during the next week. By the eighth day in hospital the patient was fully responsive. Saccades to visual stimuli in the right field of gaze were limited to about $20^{\circ}$ rightward from the mid-position. Saccades to the left were full in range. Smooth pursuit movements were saccadic in both horizontal directions, but full in range. Oculocephalic manoeuvres while the patient fixated on a stationary target produced full smooth eye movements. The patient was right handed; her speech was normal. An electroencephalogram (EEG) showed occasional low amplitude theta waves over the left temporal region but no epileptiform abnormalities. Examination one month later showed saccarlic pursuit movements to the left and right. Saccades appeared normal. During forced eyelid closure the eyes deviated to the extreme left. A repeat CT scan showed resolution of the frontal haematoma.

Oculographic study: Saccadic responses to randomly presented target steps of $5^{\circ}, 10^{\circ}$ and $20^{\circ}$ amplitude $(\mathrm{N}>15$ at each amplitude) and pursuit of $20^{\circ}$ amplitude triangular waveform targets at $0.25,0.5$ and $1 \mathrm{~Hz}(\mathrm{~N}>20$ at each frequency) were recorded three weeks after admission using DC photoelectric infrared reflection oculography. The patient was taking no medications. Eye and target signals were digitised off-line at 200 samples/s, and analysed with a PDP11 computer. 


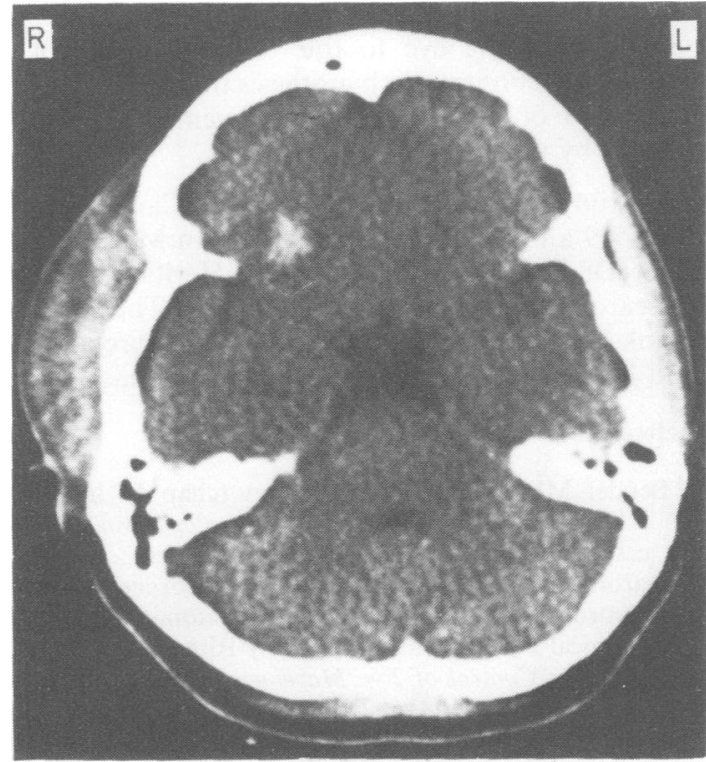

Fig 1 CT scan shows subcortical haematoma in right frontal lobe.

Saccadic latencies were abnormally prolonged ipsilateral and contralateral to the right frontal haematoma, when compared to values of 15 normal subjects (normal mean plus 2SD; table). Only for $20^{\circ}$ target steps was contralateral saccadic delay significantly greater. Rightward saccades were abnormally hypometric and more saccades were required than during leftward refixations (fig 2A). For $20^{\circ}$ target steps the mean amplitude of initial rightward (ipsilateral) saccades was $15.6^{\circ}(\mathrm{SD} 0.35)$ and of initial leftward saccades was $17.9^{\circ}$ (SD 1-1); the difference was significant ( $p<0.001$; two tailed $t$ test; df 51). Saccadic peak velocities were normal in both directions. When instructed to make saccades away from a target step (antisaccades), the patient successfully accomplished $77 \%$ of antisaccades in 31 rightward target trials and $76 \%$ in 26 leftward target trials.

Smooth pursuit of predictable targets was asymmetrically reduced toward the side of the right frontal haematoma during tracking at 0.5 and $1.0 \mathrm{~Hz}$ (fig $2 \mathrm{~B}$, table). At $1.0 \mathrm{~Hz}$ pursuit velocities were subnormal in both directions but the asymmetry was significant.
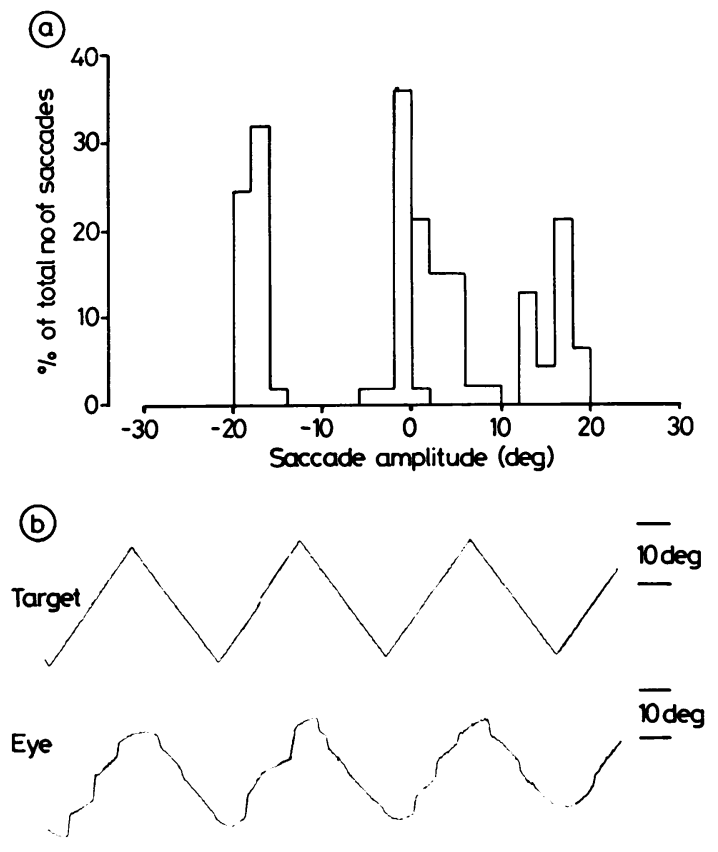

| $1500 \mathrm{~ms}$

Fig 2 a: Histogram of saccadic amplitudes to $20^{\circ}$ targets illustrates hypometria of saccades to the right (rightward positive) compared to saccades to the left (leftward negative). $b$ : Pursuit of predictable $0.5 \mathrm{~Hz}$ triangular waveform target at $20^{\circ} / \mathrm{s}$ shows faster smooth eye movements to the left (downward in figure) than to the right (upward). Since smooth pursuit gain was below unity in both horizontal directions compensatory catch-up saccades occurred during both rightward and leftward tracking.

\section{Discussion}

The gaze deviation away from the frontal haematoma and the prolonged hypometria of ipsilateral saccades was in contrast to the usual ipsilateral gaze deviation and paresis of contralateral saccades that occurs after unilateral cerebral lesions. ${ }^{2-4}$ The contralateral saccadic paresis is thought to be a manifestation of fron-

Table

\begin{tabular}{|c|c|c|c|c|}
\hline & \multicolumn{3}{|l|}{ Patient } & \multirow[t]{2}{*}{ Normal } \\
\hline & Contralateral & Ipsilateral & $p^{*}$ & \\
\hline $\begin{array}{l}\text { Saccadic latency }(\mathrm{ms}) \pm 1 \mathrm{SD} \\
5 \text { degree target } \\
10 \text { degree target } \\
20 \text { degree target }\end{array}$ & $\begin{array}{l}253+1-85 \\
304+1-62 \\
346+1-68\end{array}$ & $\begin{array}{l}277+1-69 \\
295+1-51 \\
287+1-31\end{array}$ & $\begin{array}{l}>0.10 \\
>0.10 \\
<0.01\end{array}$ & $\begin{array}{l}202+1-36 \\
212+1-37 \\
230+/-40\end{array}$ \\
\hline $\begin{array}{l}\text { Smooth pursuit gain } \pm 1 \mathrm{SD} \\
10^{\circ} / \mathrm{s} \text { target } \\
20^{\circ} / \mathrm{s} \text { target } \\
40^{\circ} / \mathrm{s} \text { target }\end{array}$ & $\begin{array}{l}0.90+/-0.11 \\
0.90+/-0.12 \\
0.51+/-0.10\end{array}$ & $\begin{array}{l}0.86+/-0.22 \\
0.82+/-0.22 \\
0.37+/-0.13\end{array}$ & $\begin{array}{l}p>0.10 \\
p<0.02 \\
p<0.001\end{array}$ & $\begin{array}{l}0.96+1-0.07 \\
0.97+1-0.06 \\
0.90+1-0.13\end{array}$ \\
\hline
\end{tabular}

Pursuit gain is the ratio of smooth eye movement velocity to target velocity.

* $p$ values are derived from two tailed $t$ tests. 
tal lobe damage. ${ }^{2}$ Deviation of the eyes away from the side of acute cerebral lesions is often a sign of thalamic haemorrhage, usually with blood in the third ventricle. $^{5,6}$ Our patient and one other reported case ${ }^{7}$ indicate that contralateral deviation can result from destructive lesions above the thalamus. The lesion in our patient involved the frontal lobe.

Epileptic cortical discharge can also cause contralateral deviation. Absence of seizure activity in somatic muscles, absence of jerking of the eyes, the long lasting deviation, and the normal EEG all militate against adversive seizures in this patient. A contracoup injury to the left hemisphere might explain leftward gaze deviation, but there were no clinical, EEG, or CT signs of left cerebral damage.

The mechanism of contralateral deviation is unknown. Stimulation of the human frontal lobe usually produces contralateral eye movements but occasionally they are ipsilateral. ${ }^{8}$ Saccades elicited by stimulation of the simian frontal eye field are predominantly contralateral. ${ }^{9}$ The effect of frontal eye field lesions on smooth pursuit has not been documented. Extensive unilateral cerebral lesions cause paresis of contralateral saccades and ipsilateral smooth pursuit. ${ }^{10}$ The unidirectional smooth pursuit defect usually signifies parietal lobe damage. ${ }^{2,3}$ The frontal lobe haematoma in our patient caused saccadic pursuit in both directions, but smooth eye movement gain was significantly lower toward the side of the lesion. The prolonged contralateral deviation might be a manifestation of imbalanced horizontal pursuit tone. Contralateral deviation of the eyes during lid closure was further evidence for cerebral ocular motor imbalance. Although this spasticity of conjugate gaze ${ }^{11}$ has not been correlated with asymmetrical pursuit, it might result from the imbalance of smooth eye movement tone caused by unilateral cerebral damage. ${ }^{3}$

An alternate mechanism of contralateral deviation might be release of reflexive contralateral saccades generated by the brainstem. Some patients with unilateral frontal lobe damage are unable to make ipsilateral saccades away from targets (antisaccades ${ }^{12}$ ) and they are unable to suppress saccades towards contralateral targets. ${ }^{12}$ The unsuppressed saccades toward contralateral targets may be thought of as a visual grasp reflex, perhaps mediated by the ipsilateral superior colliculus when released from frontal lobe control. Our patient, however, made saccades away from targets with equal facility in both directions. Further correlation of pur- suit paresis with spasticity of conjugate gaze, and deviation of the eye to the "wrong side" will be required to confirm our hypothesis that they are manifestations of the smooth eye movement imbalance caused by unilateral cerebral lesions.

This study was supported by MRC of Canada grants ME5509 and MT5404 (Dr Sharpe), an MRC fellowship (Dr Bondar) and an Alberta Heritage Medical Research Fellowship (Dr Fletcher). The authors thank Mrs R Armstrong for manuscript preparation and $\mathrm{Mr}$ P Nguyen for technical assistance.

\section{References}

${ }^{1}$ Bender MB. Neuro-ophthalmology (chap 4). In: Baker AB, Baker LH, eds. Clinical Neurology, vol 1. Hagerstown MD: Harper \& Row, 1973:1-108.

${ }^{2}$ Daroff RB, Hoyt WF. Supranuclear disorders of ocular control systems in man. Clinical, anatomical and physiological correlations. In: Bach-y-Rita P, Collins CC, eds. The Control of Eye Movements. New York: Academic Press, 1971:175-236.

${ }^{3}$ Sharpe JA. Cerebral ocular motor deficits. In: Lennerstrand G, Zee DS, Keller EL, eds. Functional Basis of Ocular Motility Disorders. Oxford: Pergamon Press, 1982:479-88.

${ }^{4}$ Holmes G. The cerebral integration of ocular movements Br Med J 1938;2:107-12.

${ }^{5}$ Fisher CM. Some neuro-ophthalmological observations J Neurol Neurosurg Psychiatry 1967;30:383-92.

${ }^{6}$ Keane JR. Contralateral gaze deviation with supra tentorial hemorrhage. Arch Neurol 1975;32:119-22.

${ }^{7}$ Pessin MS, Adelman LS, Prager RJ, Lathi ES, Lange DJ Wrong-way eyes in supratentorial hemorrhage. Ann Neurol 1981;9:79-81.

${ }^{8}$ Rasmussen TH, Penfield W. Movement of the head and eyes from stimulation of human frontal cortex. In: The Frontal Lobes. Baltimore: Williams and Wilkins Co, 1947:346-61.

${ }^{9}$ Robinson DA, Fuchs AF. Eye movements evoked by stimulation of frontal eye fields. $J$ Neurophysio 1969;32:637-48.

${ }^{10}$ Sharpe JA, Lo AW, Rabinovitch HE. Control of the saccadic and smooth pursuit systems after cerebral hemidecortication. Brain 1979;102:387-403.

${ }^{11}$ Cogan DG. Neurological significance of lateral conjugate deviation of the eyes on forced closure of the lids. Arch Ophthalmol 1948;3937-42.

${ }^{12}$ Guitton D, Buchtal HA, Douglas RM. Disturbances of voluntary saccadic eye movement mechanisms following discrete unilateral frontal lobe removals. In: Lennerstrand G, Zee DS, Keller EL (eds). Functional Basis of Ocular Motility Disorders. Oxford: Pergamon Press, 1982:497-9. 